WellBeing International

WBI Studies Repository

1985

\title{
The Green Movement: Implications for Animals
}

Ronnie Z. Hawkins

Follow this and additional works at: https://www.wellbeingintlstudiesrepository.org/acwp_epcph

Part of the Animal Studies Commons, Natural Resources and Conservation Commons, and the Terrestrial and Aquatic Ecology Commons

\section{Recommended Citation}

Hawkins, R.Z. (1985). The Green movement: Implications for animals. In M.W. Fox \& L.D. Mickley (Eds.), Advances in animal welfare science 1985/86 (pp. 269-283). Washington, DC: The Humane Society of the United States.

This material is brought to you for free and open access by WellBeing International. It has been accepted for inclusion by an authorized administrator of the WBI Studies Repository. For more information, please contact wbisr-info@wellbeingintl.org.

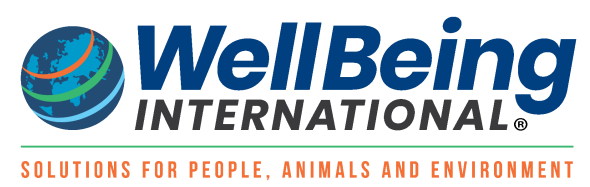




\title{
THE GREEN MOVEMENT: IMPLICATIONS FOR ANIMALS
}

\author{
Ronnie Z. Hawkins
}

P.O. Box 13253

Gainesville, Florida 32604

\section{Introduction}

The Green movement, a newly emerging political movement that is both global in scope and firmly anchored to each local region at the grassroots level, is destined to be of great import to those concerned with the status of nonhuman animals in our society. Closely allied with deep ecology and bioregionalism, Green thinking embodies an alteration in our perception of the human organism: no longer seen as separate from and superior to all the other components of the ecosystem, our species is placed in context as one among many interdependent forms of life, with the attainment of a sustainable balance among all life forms being the desired goal in designing our human activities. Translation of this viewpoint into political action is the challenge of Green organizations on several continents today.

Green political organizations are springing up in one form or another all around the globe, including here in North America, but the West German die Grünen, the Greens, are perhaps the best known and have generated a detailed platform that will provide a helpful model for an examination of Green politics and its ramifications with regard to animal issues. Briefly, the policies of die Grünen are based on four fundamental principles: ecology, social responsibility, grassroots democracy, and nonviolence. The principle of ecology entails holistic thinking as well as ecological science, and deep ecology (to be discussed in greater detail shortly) as opposed to a shallow environmentalism which seeks ecosystem protection solely out of human-centered concern. Social responsibility has been defined as "social justice and an assurance that the poor and the working class will not get hurt by programs to restruc- 
ture the economy and our consumer society ecologically," (Capra and Spretnak 1984b) and the Federal Programme of die Grünen contains a comprehensive set of guidelines for protecting and extending the rights and freedoms of human individuals. The political power of the West German Greens is deeply rooted in grassroots democracy, with many of the Greens' constituents coming from the various citizens' movements, including peace, antinuclear, ecology, feminist, and consumer groups. Priority is given wherever possible to participatory democracy, with most decision-making occurring at the level of decentralized, semiautonomous local units. The fourth principle, nonviolence, refers to a cessation of both personal and institutional violence; it is reflected in the Greens' active resistance to the nuclear arms race and other forms of militarism and in their call for an end to the oppression of women, children, and minority groups, an end to the economic exploitation of Third World peoples, and an end to the exploitation of nature and nonhuman animals as well. Three other principles are sometimes added to the first four: decentralization of all social structures into smaller, more manageable units that will have greater inherent flexibility and capacity for self-direction; post-patriarchal politics, empowering women at all levels of governance and incorporating feminist analysis in policy-making; and spirituality, appreciating and expressing an awareness of the unity of all life on a spiritual level. All seven principles, as a holistic understanding would have it, necessarily intermesh, but for purposes of discussion they have been separated and examined.

"Deep ecology" is the line of thinking that forms the philosophical backbone of the Green movement; it is currently being elaborated by philosophers such as Arne Naess, George Sessions, and Bill Devall. Its roots are traceable to the works of Spinoza, Heidegger, Saint Francis, American Indian religion, and some Eastern traditions. The writings of earlier ecological thinkers such as Thoreau, John Muir and Aldo Leopold, and poets Walt Whitman, Robinson Jeffers, and Gary Snyder have also played a significant role in the development of this philosophy. Deep ecology seeks to understand humans within the context of the entire biosphere, and this "total field" model allows us to envision the relationships among seemingly separate entities as interwoven within a single living system. In keeping with recent advances in physics and biology, natural phenomena are seen as vital, cyclical, interconnected, and diverse in qualitative ways, in addition to being describable under certain conditions as mechanical, separate, and reducible to quantifiable but nonliving parts and pieces. Beyond this integrative viewpoint, deep ecology grants what has been called biospherical egalitarianism (Naess 1973), that is, "the equal right to live and blossom", to all forms of life. In a recent ecology journal, Naess and Sessions (1984) outlined a tentative formulation of eight principles of deep ecology: 
1) The well-being and flourishing of human and nonhuman Life on Earth have value in themselves (synonyms: intrinsic value, inherent value). These values are independent of the usefulness of the nonhuman world for human purposes.

2) Richness and diversity of life forms contribute to the realization of these values and are also values in themselves.

3) Humans have no right to reduce this richness and diversity except to satisfy vital* needs.

4) The flourishing of human life and cultures is compatible with a substantial decrease of the human population. The flourishing of nonhuman life requires such a decrease.

5) Present human interference with the nonhuman world is excessive, and the situation is rapidly worsening.

6) Policies must therefore be changed. These policies affect basic economic, technological, and ideological structures. The resulting state of affairs will be deeply different from the present.

7) The ideological change is mainly that of appreciating life quality (dwelling in situations of inherent value) rather than adhering to an increasingly higher standard of living. There will be a profound awareness of the difference between big and great.

8) Those who subscribe to the foregoing points have an obligation directly or indirectly to try to implement the necessary changes.

The perspective of the deep ecologist, therefore, has been shifted from the human-centered limitations of what is presently the dominant paradigm, expanding into the complexity and compassion of Leopold's (1949) "thinking like a mountain." Deep ecology embodies what is sometimes called biocentrism as opposed to anthropocentrism: it is a matter of putting life at the center of our concern-not just human life, but all life, life in balance.

A full grasp of deep ecology goes beyond scientific knowledge and ethical consideration to a sense of spiritual oneness with the cosmos; its implication for our status as humans, far from an anthropocentrically feared diminution, is profoundly elevating and transformative. In the words of Australian activist John Seed (1983):

Alienation subsides. The human is no longer an outsider, apart. Your humanness is recognized as being merely the most recent stage of your existence, and as you stop identifying exclusively with this chapter, you start to get in touch with yourself as mammal, as vertebrate, as a species only recently emerged from the rainforest.

*The term "vital need" is left deliberately vague to allow for considerable latitude in judgement (Naess and Sessions 1984). 
An integral part of deep ecology is the awareness of the need to take action to rechannel the present destructive course of human activity. Seed continues:

As the fog of amnesia disperses, there is a transformation in your relationship to other species, and in your commitment to them..."I am protecting the rainforest" develops to "I am part of the rainforest protecting myself. I am that part of the rainforest recently emerged into thinking."

In their recently published Deep Ecology, Devall and Sessions (1985) discuss at some length the obligation to engage in nonviolent witnessing of and direct action to halt the injuries being inflicted upon the planetary systems, action which can range from public speaking, filing lawsuits, and educating politicians to sitting down in front of bulldozers. They describe ecological resistance as acting on the principles of deep ecology, likening it to befriending another species, or a mountain or river, and taking steps to preserve the peace of the greater neighborhood when the need arises. In his foreword to Ecodefense (Foreman 1985), Edward Abbey extends this analogy by comparing the latest assault upon American wilderness* to a stranger breaking down the door of one's house, threatening one's family with deadly weapons, and ransacking the place, a crime that one must defend oneself against by whatever means are necessary. Detailing the techniques of "monkeywrenching," Foreman goes beyond civil disobedience to include the incapacitation of the machinery of destruction in this defense, being careful to exclude violence to human or nonhuman life in such measures. He asserts:

Monkeywrenchers-although nonviolent-are warriors. They are exposing themselves to possible arrest or injury. It is not a casual or flippant affair. They keep a pure heart and mind about it. They remember that they are engaged in the most moral of all actions: protecting life, defending the Earth.

Foreman states that a widespread and serious ecodefense could protect millions of acres of wilderness and hundreds of threatened life forms more effectively than a Congressional act or an army of game wardens. He concludes:

John Muir said that if it ever came to a war between the races, he would side with the bears. That day has arrived.

\footnotetext{
*The Development Activities in Roadless Nonselected plan of the U.S. Forest Service, now getting under way, aims to cut over 75,000 miles of new roads into presently roadless areas and in many cases $\log$ from the center outward, thus destroying most of the last remaining large areas of natural diversity in the continental United States. Of 140 million acres of undeveloped public lands, only about 24 million are likely to be protected as wilderness; the rest will face ecological devastation within half a decade.
} 
Deep ecology thus provides the Green-oriented individual with both spiritual affirmation and an impetus toward action that can entail a very high degree of personal commitment.

If deep ecology forms the philosophical foundation of the Green movement, the translation of its concepts into appropriate human activity unique to each particular place on the planet occurs through bioregionalism. An awakening that has been taking shape predominantly in North America, bioregionalism has to do with reintroducing a sense of place into our disconnected and homogenized Western culture, rediscovering how the web of life interplays in any given natural region, be it a watershed, a mountain range, a coastal plain, or whatever, binding together the topography, climate, floral, faunal, and human communities found therein. Emphasizing that the human has a rightful place within each bioregion (or, at least, within many of them), Peter Berg has introduced the term reinhabitation, signifying the active process of learning to live in place once again. In Reinhabiting a Separate Country, Berg (1978) notes:

The boundaries of a bioregion are best described by people who have lived within it, through human recognition of the realities of living in place. All life on the planet is interconnected in a few obvious ways and in many more that remain barely explored. But there is a distinct resonance among living things and the factors which influence them that occurs specifically within each separate place on the planet. Discovering and describing that resonance is a way to describe a bioregion.

The American Indian tradition has always had a strong sense of living in place, and indeed the lack of a sense of place combined with an overemphasis on historical time has been an American Indian criticism of European culture (Deloria 1973); even European societies, however, were by necessity adapted to the conditions of their particular geographical areas until the coming of industrialism, which offered the illusion of having freed us from that seeming obligation while hastening our loss of regional character and widening the gap of our separation from the rest of the natural world. Bioregionalism is the obvious answer to the question "Decentralize into what?" - so logical a unit is it for human activity and organization that one may well wonder why our society has for so long overlooked the natural unit in deference to what is an often unwieldy, abstract demarcation arising predominantly out of historical contingency. But perhaps the most critical quality of a bioregion is found in this definition by Thomas Berry (1984): "A bioregion is simply an identifiable geographic area whose life systems are self-contained, self-sustaining and self-renewing." The concept of sustainability, once raised, forces us to confront the fact that most of our present activities are neither self-contained in space nor self-sustaining over time, from the metropolis that can exist only by spatially exploiting other bioregions 
to obtain its food and energy and relieve itself of wastes, to mistakenly self-congratulatory "growth" regions like the American Sunbelt that are seemingly unaware of the temporal limitations to the prosperity accompanying the first phase of that exponential curve. Applying the criterion of sustainability necessitates recognizing an optimal, and certainly a maximal, limit determined by the human carrying capacity for each bioregional unit, and once we achieve this realization we can begin a conscious leveling off into a steady state of appropriate design.

Decentralization into the bioregional unit can be a powerful concept to embrace if we are to free ourselves from several serious dilemmas caused by the bigness and bureaucracy to which our society currently clings. As Ozark organizer David Haenke (1984) discusses in his pamphlet Ecological Politics and Bioregionalism, recognition of natural or ecological law, as it operates specifically within each place, shows us what will work best for us too- the deceptive abstractions of economics notwithstanding, it is most efficient to operate with rather than against nature, and in decentralized units we can exercise the utmost flexibility in doing so. The present deadlock of forcing a choice between the problems of nuclear power and acid rain thereby breaks down into utilizing windpower here, capturing solar energy there, and generating some biomass for fuel across the way, depending on what is most available and practical. The myth that we must accept topsoil-depleting, pesticidesoaked monocultures of machine-harvested crops shuttled thousands of miles to market, or run the risk of starvation, dissolves into embracing permaculture, integrated pest management, regional and seasonal crop variety, and community gardens tended with local pride for satisfying local appetites. Decentralization into the bioregional unit also points us in a direction leading away from the nuclear weapons impass, since recognizing the natural law that sets a maximum size limit to fully self-governing groups of human beings and rediscovering responsible, participatory democracy enables us to let the nation-state, upon which planetary nuclear war is predicated, recede into the background and fade away.

The ways in which Green thinking and Green policies will affect nonhuman animals, directly and indirectly, are numerous. Most importantly, the old anthropocentric bias that gave humans automatic priority in every situation has been swept away; while all Green-oriented individuals may not agree on just what the animals' rights are, recognition has been granted to nonhuman animals as fellow beings whose concerns we must consider. On one level, the problems of animals cannot be separated from those of the ecosystem at large, just as those of humans as a group cannot, and hence all policies dealing with ecological considerations are of relevance to animal species. But appreciation of animals as our spiritual relations entails protection of individual creatures as well 
as members of population groups, and the platform of the West German Greens reflects this position also.

The preamble to the Federal Programme of die Grunen (1983) contains the statement "We consider ourselves part of the Green movement throughout the world," and among the most urgent of the issues they address are global ones. If our goal is sustainability of the planetary ecosystem, each diminution or disappearance of a species represents another failure in moving toward that goal, a further weakening of the web of life that supports us all. Actions must be taken at once to halt and reverse those processes leading to species extinction, from a cessation of whaling to an end to rain forest destruction, and indeed the Federal Programme calls for both. Trade in endangered species and their products is to be totally prohibited; West Germany is instructed to campaign actively for international species protection, and immediate measures are to include a ban on importation of products such as sealskins and a license requirement for certain other items. Appreciation of the gravity of the human overpopulation problem is present along with the desire for partnership with Third World peoples, and the Programme specifies that assistance for birth control must be supplied to overpopulated countries upon request. Likewise, the destructiveness of the Western development model, which is particularly severe when abruptly applied to "underdeveloped" areas, and which results in known mistakes that need not be duplicated, is recognized in the provision: "Vocational training of the less developed peoples must be promoted not so as to impart to them the failed ideas of the industrialized countries but rather to allow them to solve their problems within their means and in a way appropriate to their environment." And with the awareness that nuclear holocaust is an even quicker means of planetary destruction than the ongoing ecological degradation, the Greens demand an immediate beginning to worldwide disarmament and a global ban on the production and storage of nuclear weapons. Understanding that present economic policies underlie and encourage all these undesirable activities, die Grünen reject the major assumption made by both ends of the old political spectrum. Proclaiming "we are neither left nor right, we are in front," (Capra and Spretnak 1984a) the Greens seek to correct the mistaken belief that infinite expansion of industrial production is possible or desirable in a finite system, an error that both capitalist and communist forms of government have incorporated. While it may take many decades, indeed centuries, to restore the planet to a truly harmonious balance among populations of its different life forms, implementation of the global objectives of the Greens will assure that at least the overall trend of our society will be heading in that direction rather than in the reverse-we would sleep at night secure in the knowledge that our children's children will inherit a planet at least as 
stable, diverse, and sustainable as the one we have now, something that, sadly, cannot be said at present.

With regard to their own country, the Greens' Federal Programme contains extensive and detailed provisions aimed at protection of the ecosystem. The Greens take the position that "Protection of native animals and plants in their natural surroundings must be given priority over economic development plans." Large areas are to be maintained or restored as nature preserves, and native species which have been exterminated in areas are to be reintroduced. Attention is paid to protection of shorelines, saltmarshes, and wetlands, and further drainage measures are to be prohibited. In addition to preserves, protection of species and natural areas is to be extended into the places where people live and work. "Open planning" is demanded in regard to all new building, with environmental protection organizations to be included in all planning procedures and granted the right to bring citizen lawsuits. Wooded areas, thickets, and hedges removed by building are to be completely replaced. Road building is to be restricted to the completion and maintenance of the existing road system (in effect delimiting an optimal size for the society as well as ensuring protection of natural areas), with the people formerly employed in road building to be retrained, perhaps in landscape preservation or energy conservation activities. A ministry of the environment is to be established to correct present conditions of habitat degradation and species extirpation, deforestation, soil erosion, and contamination of soil, water, and air by toxic chemicals and radioactivity. Immediate measures are to be taken to reduce the emission of pollutants by industry, power plants, and motor vehicles, with an absolute ban on known carcinogenic pollutants; emphasis is to be put upon recycling, as well as minimizing and detoxifying the waste that is produced. The Greens oppose the construction and operation of nuclear power plants.

Agriculture is to be closely scrutinized as to its effects on the ecosystem: "As far as damage to the environment goes, agriculture can now compete with industry." The Federal Programme states that "The supreme aim of agricultural policy must be the healthy nutrition of the population," which presupposes healthful foodstuffs produced on healthy soil through an ecologically oriented mode of production. Economic policies which have heretofore favored large, centralized, industrialized and chemically dependent methods of agriculture and adversely affected organic or ecological agriculture and small- to medium-sized farms must be reversed. Monocultures and intensive livestock production are to be replaced by mixed farming, with on-site interchange of fertilizer, feeds, and energy sources where possible. Chemical pesticides and herbicides will eventually be completely supplanted by appropriate cropping, biological controls and other ecologically sound, soil health-enhancing measures; and during the readjustment period, stricter legal limits are to be imposed on pesticides, and residues closely monitored. 
Fishing and forestry are also to be readjusted to ecological soundness. The Federal Programme makes the (for some) radical statement that "The main task of forestry is to sustain the ecological stability of the forest. Timber production for profit must be subordinate to this aim." There is to be a shift away from the species-poor stretches of even-age monoculture to more natural, mixed foliage of native types and differing age composition which are much more favorable to a diversity of wildlife. Individual selective felling is to replace clear-cutting, accompanied by a restriction of large machinery and the eventual banning of chemical controls. Corrective measures with respect to fisheries include immediate reduction of catch quotas on certain depleted species to allow stocks to recover, protected zones, closer controls over fishing grounds, mesh sizes, and closed seasons, a prohibition on catching young fish as fish meal, steps to reduce waste of fish products, and support for techniques that favor small- and medium-sized fishing companies.

Going beyond protection of the species within the ecosystem, the Federal Programme of die Grünen includes a number of provisions for protecting the rights of individual nonhuman animals. "Animals must no longer be legally considered as 'objects,' but should be granted a special legal status." Torture of animals is prohibited and to be "severely punished," and strict regulations on the keeping and transport of domestic and captive wild animals are proposed. In agriculture, animals are to be kept in ways that are "fair to their species and nature," and "Cruel battery farming must finally be abolished." As an immediate measure, obligatory labeling of animal products as to their origin (e.g., battery vs. free-range eggs) is demanded. Animal breeding must also be "fair to the species," and genetic manipulation of animals as well as humans is rejected. Industrial animal production, in addition to its cruelty to the animals in question, is to be curtailed also in the interests of supporting small farms and protecting human jobs.

The issue of laboratory experimentation upon animals is also raised specifically: "In the name of science, thousands of animals daily undergo fatal experiments, e.g., for the testing of chemicals, weapons, medicines and cosmetics... .Experiments on animals should be replaced by suitable proven alternative methods (e.g., tissue culture or computer simulation in the medical sphere). A comparison must be made by legal experts between the expected benefit from the experiment and the right to life of the animals concerned." Repetition of experiments is to be avoided by establishment of a central data bank for all permitted animal experiments and the obligation to publish data already obtained. The value of psychological experiments on animals is noted to be "highly questionable." Responsibility for enforcement of animal protection guidelines in both agriculture and research is to be transferred from the ministry of agriculture to a ministry of the environment, to be created. 
While this platform may not go quite far enough to satisfy the most committed animal rights activists, it clearly provides a framework within which many improvements in the status and condition of animals can be made. All of those who care about animals should agree on the necessity for vigorous pursuit of ecosystem stabilization and rehabilitation of endangered and threatened wild species. In regard to domestic animals, certain changes - decentralization and scale reduction, with the aim of eventual elimination of industrialized agriculture, for instance-will go far to correct the worst institutional abuses. But much more work needs to be done on this front, and, since the Green program, taken as a whole, represents an attempt to define an optimal scheme for all our human activities, what constitutes an ideal position for domestic animals must be reexamined critically in the years to come if we are to move away from all forms of exploitation. There are those who would advocate the eventual elimination of all human-animal dependence, including the phasing out of all farm and companion animals over a period of time, allowing them to revert over generations back to autonomous wild beings. Others consider the small farm situation in which the animals are accorded respect and a pleasant livelihood in exchange for certain "products," which might or might not include flesh, to be an appropriate, minimally exploitative and overall mutually beneficial state.

Certainly the application of an ecological analysis to our companion animals is overdue: we must assume responsibility for correcting an overabundance of domesticated carnivores, the excess of which is not supportable by the ecosystem and individuals of which, having weakened survival skills and disrupted social patterns, are doomed to prolonged suffering and starvation when not in the care of a human. An accounting must also be made of the meat presently being used to maintain them, which may ultimately be contributing to a toll taken on marine mammals and other diminishing species as well as domestic cattle and poultry. Trade in wild-captured tropical birds, coral reef fish and exotic reptiles for the "pet" trade should be curtailed on ecological grounds, and a total ban on removal of any wild species, endangered or not, from its native habitat, except perhaps for the most pressing scientific purposes in the interests of that species, is not unthinkable. The raison d'être of the fur trade likewise needs reevaluation, and a new definition of our relationship to so-called "pest" species is clearly called for, with peaceful coexistence as a goal. In regard to laboratory experimentation on nonhuman animals, the shift to emphasis upon a holistic understanding of health should hasten the cutting back on invasive exploitation, as we recognize the inherent limitations of the mechanistic "animal model": neither the importance of the total field of interaction in health and illness, nor the importance of inner motivation in the active pursuit of health, can be addressed adequately by studying caged and coerced animals. Under the new model, much scientific progress can be anticipated 
in the area of interspecies communication, through noninvasive exploration, in the appropriate context, of the language structure and social organization of the species in question-meeting wherever possible on the animal's terms rather than solely on human ones.

The West German Greens make no mention of vegetarianism in their Programme, although one would expect a considerable number of adherents among them by personal choice, out of concern for ecological, health, and spiritual considerations; there is also no specific attention to the issue of hunting, though presumably if such activity is to occur it will be only under strict ecological guidelines. As we fashion an optimal level of human-animal interaction, we humans are faced with the choice of just how predatory we shall allow ourselves to be. Our biological capacity provides us with a high degree of flexibility, and arguments can be made both for the predatory role being as much our right as that of many other members of the ecosystem, as well as for the minimalization of our carnivorous practices so as to be more in keeping with the dietary habits of the great apes, and hence with our own physiological adaptations. Another facet to the hunting question concerns the traditions of native peoples throughout the world. While appreciation of the cultural diversity of human beings is perhaps as much a Green value as preservation of biological diversity, it must be admitted that in many areas irreversible changes have occurred, and where the introduction of technological advantages to traditional hunting is working to the detriment of the hunted species, such practices will have to be curtailed. It is to be hoped that, where new cultural norms will inevitably arise from cultural mingling, respect for the lives of nonhuman animals will prevail and the conscious choice for a reduction in exploitation will be made.

In working out their ambitious program, the West German Greens have not been free of conflict, which has arisen as much out of the diversity of their constituency and the struggle to maintain noncompetitive ideals within the established structure of government as out of the difficulty of introducing new ideas, some of which require considerably more development, into the political arena. Perhaps the remarkable thing is that the party has functioned as well as it has to date. Temporary allies on different pieces of legislation may come from either camp of old-paradigm politics, as illustrated by the Freiburg proposal to ban the salting of streets in winter because of its detrimental effect on trees; the right-leaning Christian Democrats voted with the Greens, while the traditionally left-wing Social Democrats put the protection of human jobs, in this case those of the street-salters, above the ecological considerations. The split is indicative of the kinds of conflict and compromise that will arise in making the transition to an ecologically sound society, and demonstrates the need for the kind of conversion programs and 
job retraining called for by the "social responsibility" principle of the platform. Obviously, since the vote that sent a Green contingent into the West German Bundestag in March of 1983 was barely over the mandatory 5 percent necessary for inclusion under their system of proportional representation, there is a long way to go before many of the more visionary proposals set forth begin to see implementation. What is perhaps most significant at this time is that the goals, in particular the overriding goal of attaining a sustainable human society on the planet, have been drawn up for all to see, and the presence of a Green voice, however small, in government will assure that they are kept before our eyes.

There are now Green political organizations within Great Britain, most European nations, Australia, New Zealand, Canada, and Japan, and a Green organization is currently taking shape at the national level in the United States. The Cumberland Greens, the Los Angeles Greens, and other Green groups have already formed at the local and regional level, and they join a number of bioregions that have already developed a high degree of ecopolitical awareness, such as Shasta, in northern California, and Ozarkia, straddling Arkansas and Missouri. In the "Green Alternative-It Can Happen Here," the concluding chapter of Green Politics, by Fritjof Capra and Charlene Spretnak (1984b), several possible forms are outlined for the Green movement in the United States, including a network linking decentralized Green groups, a national membership organization that might include a political action committee but would not sponsor candidates, Green caucuses that could work within both the Republican and Democratic parties, and an actual Green party that would run candidates in elections. Since the United States, unlike West Germany and some other countries, does not have a system of proportional representation, and since a third party traditionally fares poorly in American politics, the success of an actual Green party appears somewhat dubious in America at present. However, while electoral politics at the national level may present disadvantages for the budding Green movement, other American traditions are in its favor, from a historical beginning arising out of grassroots democracy to considerable recent experience with activism through the peace movement, the feminist movement, and different environmental and animal protection organizations, to name a few, and many of these latter groups are beginning to appreciate the way in which their various agendas begin to merge past a certain point. Spretnak suggests five layers for Green organization: local, bioregional, state, macroregional, and national; the major thrust of most Green political activity will most likely take place at the local and bioregional level, with the preexisting bioregional consciousness in some areas providing a ready-made framework for initiating an ecological politics. One such group is the 
Ozark Area Community Congress, which has convened five successive participatory congresses and maintains standing committees dealing with almost every aspect of living in the Ozarks: agriculture and forestry, water, energy, health, education and communications, economics, communities, spiritual and cultural concerns, feminism, and peace; committee members educate themselves, make resolutions to translate ecological law into appropriate human activity in each category, and as much as possible put these activities into practice.

One of the first steps in awakening people to Green awareness is introducing them to their bioregion's characteristic plants and animals and their habits, and a number of efforts in that direction are currently ongoing in the United States. The Ozark Area Community Congress, for example, puts out a "bundle," a sampler packet containing materials representative of life in the Ozarks, among which is information on Ozark flora and fauna and their seasonal changes within the Ozark year. Other groups working to focus attention on the nonhuman life in their area include Peter Berg's Planet Drum Foundation, putting on programs in and around San Francisco and generating publications including a tri-annual bioregional newspaper entitled Raise the Stakes, and Nancy Morita's "Wild in the City" project (sponsored by Planet Drum), which is seeking to reintroduce and strengthen the populations of some of San Francisco's native wild species, such as peregrine falcons, brown pelicans and California sea lions. To make San Franciscans aware of the wild creatures that once inhabited the area as well as of present indigenous species, her "Wild in the City" poster/map compares the city of today with the native bioregion of 250 years ago, and she and others have been known to paint "ghost" hoof prints and paw prints of the vanished tule elk and grizzly bear down city sidewalks where, before the sidewalks came, these wild ones used to roam. All Species Day celebrations, initiated in 1978 in San Francisco by Ponderosa Pine and continued through the efforts of Chris Wells and others, have now been held in over a dozen different cities; children are encouraged to choose a species they feel close to, learn about its habits and needs and personify it in some way through costume and theatre, coming away with a new understanding of the animals' lives as well as their own.

More than two hundred participants gathered for the First North American Bioregional Congress in May of 1984, just outside Kansas City, Missouri; at that time a Green politics committee took shape to address the interest in formation of a Green political organization within the United States. The following August, a meeting of sixty activists, predominantly representatives of ecological, community, and peace groups, was held in the Minneapolis-St. Paul, Minnesota, area, out of which has emerged the Interregional Committee of Correspondence to facilitate the growth of the Green movement in America. A formal founding convention for a Green organization on the national scale is 
being planned for the near future. Those who manifest a concern for nonhuman animals and who are interested in what the coming Green movement will portend in their regard are strongly urged to become involved at some level.

For more information on the Wild in the City Project, readers may contact Nancy Morita, director, at 6 Cypress, San Anselmo, CA, 94960. Information on Planet Drum publications, activities, and newspaper subscriptions may be obtained from: Planet Drum Foundation, Box 31251, San Francisco, CA, 94131. Information on sponsoring an All Species Day celebration may be obtained from Chris Wells, 538 Aqua Fria, Sante Fe, NM, 87501. The Interregional Committee of Correspondence may be reached at PO Box 40040, St. Paul, MN, 55104. 


\section{References}

Berg, P. 1978. Reinhabiting a Separate Country. San Francisco: Planet Drum Foundation.

Berg, P. 1981. Devolving beyond global monoculture. CoEvolution Quarterly. 32:24.

Berry, T. 1984. Bioregionalism: A better way to understand where you live. (Interview). The Tarrytown Letter. 41:3-5.

Capra, F. and Spretnak, C. 1984a. Who are the Greens? New Age Journal. April: 34.

Capra, F. and Spretnak, C. 1984b. Green Politics: The Global Promise. New York: E.P. Dutton, Inc.

Deloria, V., Jr. 1973. God is Red. New York: Grosset and Dunlap, Inc.

Devall, B. and Sessions, G. 1985. Deep Ecology. Layton, Utah: Peregrine Smith Books.

die Grünen. 1983. Programme of the German Green Party. Fernbach, H., trans. London: Heretic Books.

Foreman, D. 1985. Ecodefense: A Field Guide to Monkeywrenching. Tucson, AZ: Earth First! Books.

Haenke, D. 1984. Ecological Politics and Bioregionalism. Drury, MO: New Life Farm. Leopold, A. 1949. A Sand County Almanac. Oxford University Press, Inc.

Naess, A. 1973. The shallow and the deep, long-range ecology movement. A Summary. Inquiry. 16: 95-100.

Naess, A. and Sessions, G. 1984. The basic principles of deep ecology. Earth First! 4(6): 19.

Seed, J. 1983. Anthropocentrism. Earth First! 3(6): 15. 